\section{On the Line Spectra of the Elements.}

Prof. STONEY seems to agree with me that I have given an obvious exarnple of a motion for which the theorems in chapter iv. of his memoir do not hold good. Theorem B, page 59I, runs thus : "Any motion of a point in space may be regarded as the co-existence and superposition of one definite set of partials which are the pendulous elliptic motions determined as above, \&c." It is indeed obvious that a uniform motion in a straight line cannot be regarded in this manner, not even approximately for any length of time, if the set of partials are required to be definite. I might have given an example of a limited motion, e.g: $x=\sin t^{2}$, which equally contradicts the theorem, but $I$ thought a more obvious example would convince Prof. Stoney more easily. I think, indeed, that the reasoning in chapter iv. of his memoir is erroneous. But I do not say that therefore Prof. Stoney's views on the cause of the line-spectra are wrong They may be right, although the argument in chapter iv, is not. Why this criticism is not legitimate $I$ do not see. For no slight alterations or additions would set those theorems right, as there is a palpable mathematical error at the bottom of it.

Technische Hochschule, Hanover, July 9.

C. RUNGE.

\section{The Grammar of Science.}

THE exposition of the Newtonian laws as given by Thomson and Tait has unfortunately been taken as the basis for the treatment of the laws of motion by all elementary text-book writers in the English tongue since the publication of the great "Treatise on Natural Philosophy." When that exposition is attacked we are told that Newton introduced a qualifying context which has been omitted from the exposition. In other words the current statement of elementary dynamical principles is thrown overboard in favour of Newton pure and simple. On the other hand when Prof. Tait uses an expression which is totally opposed to that principle of the "subjectivity of force" which C.G.K. claims that Prof. Tait was the first, or among the first, to propound, we are told that this expression was obviously suggested by "Newton's own anthropomorphic language." C.G.K., I take it, admits that the Newtonian Laws of Motion are illogical and unphilosophical when stated by Thomson and Tait without Newton's modifying context. I propose therefore to shortly publish a criticism of the laws of motion as accompanied by that context of Newton's which does not appear in Prof. Tait's textbooks. I trust C. G. K. will not then turn round on me and say, "Oh, yes, but this has nothing to do with Prof. Tait ; it is Newton's own anthropomorphic language."

Lastly, as to the origin of the doctrine of the "subjectivity of force," which to my mind is just as much or as little valid as the "subjectivity of matter," I would remind C. G. K. that the first two parts of Kirchhoff's "Mechanik" were published in I874, and were then only the publication of lectures of an earlier date. Philosophers before Kirchhoff taught the doctrine of subjectivity, but he, and not the author of the "Dynamics of a Particle," was the physicist who first helped many of us out of the mental obscurity as to dynamical principles produced by our study of the expositions of the laws of motion due to the Edinburgh school. KARL PEARSON.

\section{"Are the Solpugidæ Poisonous?"}

In reference to this question, propounded by Mr. Bernard in your last issue, I should be inclined to answer in the negative. I captured several specimens of Solpuga chelicornis in the Transvaal, and on one occasion witnessed a persistent attack made on this "spider" by a bird which appeared to be the Cape wagtail (Motacilla capensis). Had the Solpuga possessed poisonous qualities the attack would probably not have been made.

The specimens taken by myself exhibited no signs of pug. nacity, but always sought refuge in headlong flight to the neares cover.

Russell Hill, Purley, Surrey, July 8.

Hairlessness of Terminal Phalanges in Primates.

I OBSERVE that, in your report of the proceedings of the Zoological Society, you allude to my paper on "a seemingly new diagnostic feature of the order Primates," viz. that the terminal phalanges are destitute of hair.

NO. I I 85 , VOL. 46$]$
Since the paper was read I have found that this feature is not of ordinal value. But it is of sufficiently general occurrence to merit inquiry touching its distribution in different species.

Therefore I have withdrawn publication of the paper for the present.

Oxford, July $\mathrm{x}$. GEORGE J. ROMANES.

\section{Mental Arithmetic.}

REFERRING to the articles on "Mental Arithmetic" in NATURE, vol. xlv, p. 78 and 198 , I beg to state that there also exists a very clearly written little text-book on arithmetic founded entirely on the principles mentioned by Mr. Clive Cuthbertstone. The title is "Neuer Unterricht in der Schnellrechen-Kunst," by C. Jul. Giesing, Editor, Carl Schmidt, in Doebeln (Saxony). Price I mark 80 pf. G. DAEHNE.

Dresden-Blasewitz, "Isis," July 9.

Jackals.

THE incident of the jackals entering Howrah brings to my memory that this winter jackals entered the suburban town of Bournabal, in the Smyrna district of Western Asia Minor. This last winter being severe, it was noticed in the papers that rabies had extended to wolves and jackals, and to this circumstance was attributed their entering the villages and attacking people, and also their attacking the domestic animals.

Hyde Clarke.

\section{WEIGHT.}

THE following remarks are presented with the object of reducing the increasing gap which is growing between the treatment of the fundamental ideas of Dynamics, as taught in our academical text-books from the standpoint of verbal abstraction, and the ideas and language of those who have to deal with the actual phenomena of Nature as a reality.

1. According to the precise legal definitions of all our successive Acts of Parliament on "Weights and Measures," the reight of a body is the quantity of matter in the body, as measured out by the operation of weighing it in the scales of a correct balance.

The body to be weighed is placed in one of the scales, and is equilibrated by standard lumps of metal, stamped as pound weights, or kilogramme weights, or hundred weights, or ton weights, and the sum of these weights is called the weight of the body.

In the words of the Act of Parliament, i $\delta$ and is Victoria, c. 72 , July 30,1855 , the British pound weight is defined as a weight of platinum, marked P.S., I 844, I lb., deposited in the Office of the Exchequer; and the Act goes on to say that this lump of metal "shall be the legal and genuine standard measure of weight, and shall be and be denominated the Imperial Standard Avoirdupois Pound, and shall be deemed to be the only standard of weight from which all other weights and all other measures having reference to weight shall be derived, computed, and ascertained, and one equal seven thousandth part of such pound avoirdupois shall be a grain, and five thousand seven hundred and sixty such grains shall be and be deemed a pound troy."

In defining the unit of length, the standard yard, the temperature must be defined, $62^{\circ} \mathrm{F}$. in the Act of Parliament; but in defining the pound weight, there is in the Act no mention of temperature, height of barometer, height above sea-level, latitude, longitude, date and time of day, establishment of the port, \&c., or of any other cause tending to alter the local value of $g$.

Details of the temperature and density of the air are only required when defining the volume of the gallon of Io lbs. of water, or when making accurate copies of the standard platinum pound weight in some other metalbrass or iron, for instance--when a correction for the l buoyancy of the air must be made; and it is to cover 